\title{
FILSAFAT ILMU KARL R. POPPER DAN THOMAS S. KUHN SERTA IMPLIKASINYA DALAM PENGAJARAN ILMU ${ }^{1}$
}

\author{
Oleh: \\ Slamet Subekti \\ Jurusan Sejarah Fakultas Ilmu Budaya Universitas Diponegoro \\ Jl. Prof. H. Soedarto, SH Tembalang Semarang 50275 \\ E-mail: slametsubekti01@gmail.com
}

\begin{abstract}
This article discusses about philosophy of science according to Karl R. Popper and Thomas S. Kuhn. There are similarities and differences between their views about how progress and what function of science.Apparently both Popper and Kuhn agree that science does not proceed by induction. However Kuhn disagrees with the view that science progresses by falsifiability through conjectures and refutations, but occurance by paradigm shift. Popper and Kuhn's disagreement amounted to a distinction between two functions within the practice of science, one of criticism (Popper) and one of puzzle solving (Kuhn).Science education implies the teaching and learning of science interesting and fruitful in one hand, and teachers should be role models to students in the other hand.
\end{abstract}

Keywords:falsifiability, conjectures and refutations,paradigm shift, criticism, puzlle solving.

\section{PENGERTIAN}

Pengertian ilmu merupakan padanan kata "scientia" berasal dari bahasa Latin,yang berarti "pengetahuan" dan selanjutnya mengacu pada usaha sistematis yang membangundan mengorganisir pengetahuan dalam bentuk eksplanasi yang dapat diuji dan prediksi tentang alam semesta. Filsafat ilmu berkaitan dengan semua asumsi, landasan, metode, implikasi dari ilmu, dan dengan penggunaan ilmu(http://web.stanford.educlasssymsys13 0 Philosophy\%of\%20science.pdf).

Karl Popperdan Thomas Kuhn adalah dua tokoh terkemuka filsafat ilmu abad ke20. Ide-ide beliau bahkan menjadi arusutama kebudayaan, karena konsep-konsep filsafat ilmuyang praktis dijadikan panduan parailmuwan (https://www.academia.edu/ 7491614/KARL_POPPER_VERSUS_THO MAS_KUHN).

Pembahasan makalah ini diawali dengan uraian tentang garis besar filsafat ilmu Karl R. Popper dan Thomas S. Kuhn, dilanjutkan dengan perbandingan pemikiran kedua tokoh tersebut khususnya tentang kemajuan ilmu, dan diakhiri dengan implikasi pemikiran mereka dalam pengajaran ilmu di lingkungan pendidikan di negara kita.

\section{FILSAFAT ILMU KARL R.POPPER}

Sir Karl Raimund Popper (1902-1994) adalah seorang filsuf Austro-British dan profesor pada London School of Economics (LSE). Beliau lazim dipandang sebagai salah seorang filsuf ilmu terbesar pada abad ke-20.

\footnotetext{
${ }^{1}$ Makalah dipresentasikan dalam kelas Filsafat Ilmu pada Magister Ilmu Sejarah FIB Universitas Diponegoro pada 31Oktober 2015 ini telah diperluas. Ucapan terima kasih kepada Dr. Sindung Tjahyadi (Fakultas Filsafat UGM) atas kesempatan diskusi di kelas Biologi UGM pada 4 November 2015.
} 


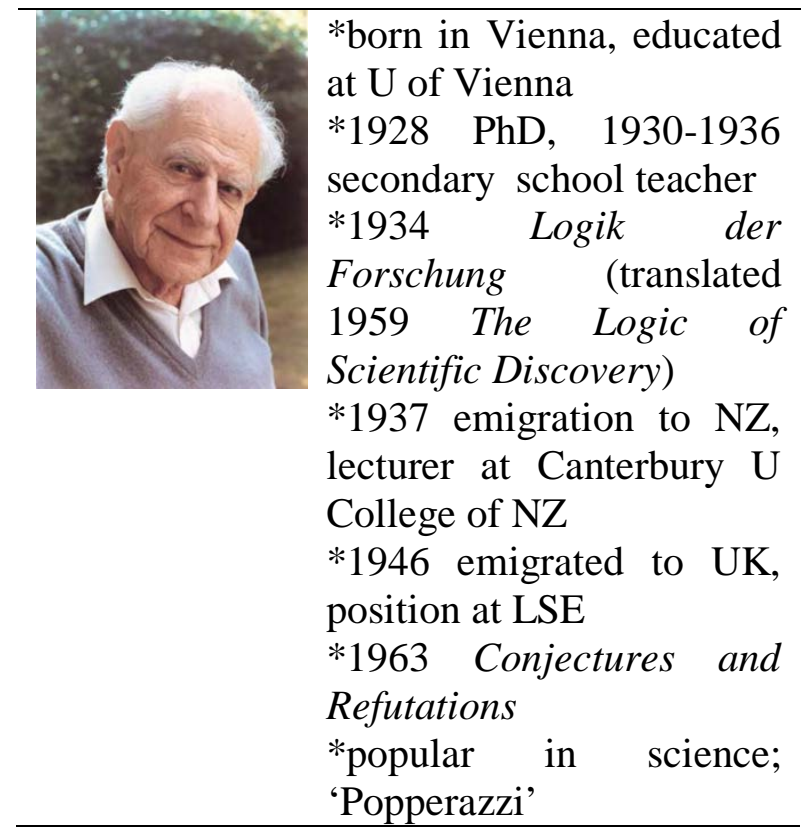

Sumber: http://philosophy.ucsd.edu/ faculty/ wuthrich/

Pandangan Popper tentang ilmu terdiri dari dua unsur: kriteria demarkasi antara ilmu dan metafisika, dan deskripsi tentang hakikat metodologi ilmiah. Unsur pertama berkaitan dengan isu berkaitan dengan status ilmu dalam spektrum luas dari pengetahuan khususnya dalam memandang ilmu-ilmu sosial. Unsur kedua berkaitan dengan isu tentanghakikat ilmudan bagaimana kemajuan ilmu (https://www.academia.edu/7491614/KAR L_POPPER_VERSUS_THOMAS_KUHN. Metode ilmiahmenurut Popper ditandai dengan proposisi dari teori-teori maupun usaha dugaan-dugaan (conjectures) dan penolakan-penolakan(refutations) teoriteori tersebut. Popper menyajikan ide tentang falsifiability sebagai cara untuk membedakan teori ilmiah asli (genuine scientific theories) dari teori ilmiah-semu (pseudoscience). Popper menggunakan istilah "Rasionalisme Kritis" (critical rationalism) untuk mendeskripsikan filsafatnya. Berkaitan dengan metode ilmiah, istilah tersebut mengindikasikan penolakannya terhadap Empirisme Klasik (classical empiricism), serta telah keluar dari pandangan kaum observationalist- inductivist klasik tentang ilmu. Popper menyatakan secara tegas menentang pandangan kaum observationalistinductivist, dengan berpegang bahwateoriteori ilmiah pada hakikatnya abstrak, dan hanya dapat diuji secara tidak langsung, dengan mengacu pada implikasiimplikasinya. Beliau juga berpegang bahwateori ilmiah, dan pengetahuan manusia pada umumnya, adalah conjectural maupun hypothetical yang sifatnya tidak dapat direduksi, dan yang berasal dari imaginasi kreatif dalam hubungan untuk memecahkan masalah-masalah yang muncul dalam setting historico-cultural khusus(https://www.academia.edu/7491614 /KARL_POPPER_VERSUS THOMAS KUHN).

Bagan 2. Perubahan ilmu melalui siklus conjenctures dan refutation

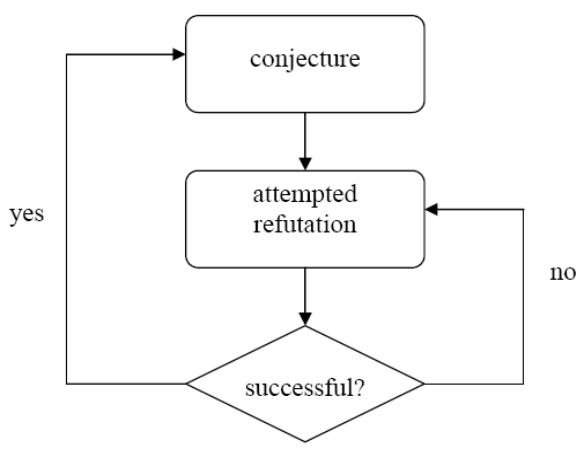

Sumber: http://philosophy.ucsd.edu/ faculty/ wuthrich/

Jadi secara logis, tidak ada sejumlah hasil (outcomes) positif pada level pengujian eksperimental dapat mengkonfirmasi satu teori ilmiah, tetapi satu contoh-tandingan (counterexample) tunggal adalah decisive secara logis: yang menunjukkan teori, dari padanya kesimpulan ditarik, menjadi salah. Istilah falsifiable bukan berarti sesuatu dibuat salah, melainkan bahwa, jika sekiranya salah, dapat ditunjukkan dengan observasi atau eksperimen. Pandangan Popper tentang asimetri logis (logical asymmetry) antara verification dan falsifiability merupakan inti dari filsafat ilmunya. Itu juga yang menginspirasi beliau 
untuk mengambil falsifiability sebagai kriteria demarkasi antara ilmiah asli, dan yang bukan: "satu teori harus dipandang ilmiah jika, dan hanya jika, ia dapat difalsifikasi”.

Demikianlah, Popper menegaskan bahwa kemajuan ilmu melalui proses dugaan (conjecture)dan penolakan (refutation). Beliau merangkumkan beberapa fitur penting proses tersebut sebagai berikut:

- Sangat mudah untuk "memverifikasi" bukti; maka memverifikasi bukti ini tidak ada nilai intrinsik.

- Dalam penggunaan tertentu, prediksiprediksi akan berisiko.

- Teori-teoriakan lebih baik (mempunyai banyak content) sebanyak mungkin membatasi pada apa yang bisa terjadi.

- Teori-teori yang tidak dapat tertolak dengan pengamatan yang mungkin itu bukan ilmiah (kriteria demarkasi).

- untuk "menguji" satu teori dalam artian serius adalah dengan mencoba untuk menunjukkan kesalahannya.

- Bukti akan mengokohkan (corroborates) satu teori jika lulus dari pengujian yang serius (genuine).

Proses ini berlangsung dimulai dengan dugaan (conjecture) dan dicoba untuk menolaknya (falsify); selanjutnya bergerak pada conjecture berikutnya, demikian seterusnya, sampai ditemukan satu conjecture yang tidak dapat difalsifikasi. Jika kita kesulitan untuk memfalsifikasinya, maka teori tersebut terkokohkan (corroborated). Hal ini bukan berarti bahwa teori tersebut mempunyai tingkat probabilitas yang tinggi. Teori tersebut mungkin masih improbable memberikan bukti. Kita hanya menerima teori-teori ilmiah secara tentatif, seraya melanjutkan percobaan untuk menolaknya. Di sini "penerimaan tentatif" bukan berarti untuk percaya bahwa teori-teori itu benar, atau bahkan menjadi sangat percayaakan kebenarannya.(http://www.soc.iastate.edu/s app/phil_sci_lecture08.html)

III. FILSAFAT ILMU THOMAS S. KUHN
Thomas Samuel Kuhn(1922-1996) adalah seorang ahli fisika, sejarawan, dan filsuf ilmu berkebangsaan Amerika yang kontroversial karena karyanya $\underline{T h e}$ Structure of Scientific Revolutions (1962) telah berpengaruh secara mendalam baik dalam lingkungan akademik maupun populer, yang memperkenalkan istilah "paradigmshift"(https://www.academia.edu /7491614/KARL_POPPER_VERSUS_TH OMAS_KUHN).

Bagan3.Riwayatsingkat Thomas S. Kuhn

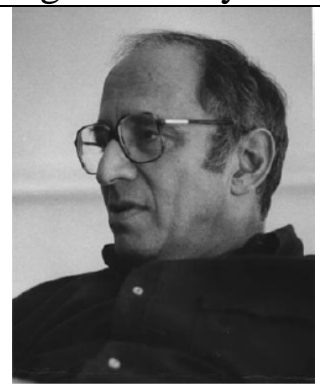

*born in Cincinnati $\mathrm{OH}$, educated at Harvard (physics)

* $1949 \mathrm{PhD}$, taught at Harvard, Berkeley, Princeton, MIT

*1962 The Structure of ScientificRevolutions *1977 The Essential Tension: SelectedStudies in Scientific Tradition andChange

\section{Sumber: http://philosophy.ucsd.edu/ faculty/ wuthrich/}

Kuhn membuat beberapa klaim terkenal berkaitan dengan kemajuan pengetahuan ilmiah: bahwa bidang ilmiah berlangsung periodic "paradigm shifts" ketimbang bergerak maju dalam satu jalur linear dan berkelanjutan; bahwa paradigm shifts tersebut membuka pendekatanpendekatan baru untuk memahami apa yang oleh para ilmuwan tidak pernah dipandang valid sebelumnya; dan bahwa pengertian tentang kebenaran ilmiah(scientific truth), pada momen tertentu, tidak dapat dibangun sendiri dengan kriteria objektif melainkan didefinisikan dengan satu konsensus dari masyarakat ilmiah (scientific community).

Paradigma-paradigma yang

berkompetisi seringkali incommensurable; yaitu, mereka berkompetisi pandangan 
tentang realitas yang tidak dapat direkonsiliasi secara koheren. Oleh karena itu, pemahaman kita tentang ilmutidak akan pernahsepenuhnya"objectivity"; kita harus mempertimbangkan juga perspektif subjektif (subjective perspectives).

Bagan 4. Perubahan ilmiah: ilmu normal dan evolusi ilmiah

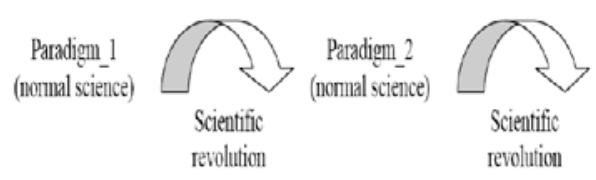

Sumber: http://philosophy.ucsd.edu/ faculty/ wuthrich/

Pandangan Kuhn tentang ilmu tampak bertolak belakangdengan pandangan Popper. Kuhn menegaskan bahwa ilmubukan maju melalui akumulasi linear dari pengetahuan baru, tetapi berlangsung periodic revolutions, disebut pula "paradigmshifts" dimana hakikat penyelidikan ilmiah dalam satu bidang tertentua dalam abruptly transformed. Kuhn memperkenalkan konsep paradigm shift untuk menandai situasi dalam sejarah ilmu dimana satu teori ditinggalkan untuk mendukung teori lain, sebagai hasil dari krisis yang didorong oleh kemunculan sejumlah teka-teki (puzzles) yang tidak dapat dipecahkan dalam konteks kerangka teori lama (old framework). Pada umumnya, ilmuterbelah ke dalamtiga tahapan yang berbeda. Tahap pertama adalah prailmiah (prescience), ditandai dengan kurangnya central paradigm. Selanjutnya diikuti dengan "normal science", tahapketika parailmuwan berusaha untuk memperluas central paradigm dengan "memecahkan teka-teki”(puzzle-solving). Dipandu oleh paradigma, normal science ini sangat produktif: "ketika paradigma berhasil, ilmuwan akan mampu memecahkan berbagai masalah ...dan ini tidak akan pernah dilakukan tanpa komitmen pada paradigma "(https://www.academia.
edu/7491614/KARL_POPPER_VERSUS THOMAS_KUHN).

Selama periodenormal science, kegagalan untuk menyesuaikan dengan paradigma dipandang bukan sebagai penolakan paradigma, tetapi sebagai kesalahan dari peneliti, ini kontradiksi dengan kriteria falsifiability Popper. Sebagaimana anomali (anomalous) yang dihasilkan, maka ilmu mencapai 'krisis', pada satu titik paradigma baru, dimanateori lamaterimbas anomali akan digeser kerangka teori yang diterima. Hal ini disebut dengan 'revolutionary science'.

Lazim terdapat gambaran tentang ilmu tetapi sangat menyederhanakan melihat ilmu sebagaiusaha kumulatif secara ketat (kemajuan ilmudengan menemukan sebanyakmungkin cara tentang bekerjanya dunia). Istilah "sebanyak mungkin" menyarankan tidak ada yang hilang. Kuhn menegaskan bahwa sebaliknya terdapat kehilangan maupun perolehan substantial ketika terjadi paradigm shifts. Berikut ini beberapa contoh.

- Beberapa problem tidak mensyarat-kan solusi, karenamereka dibuat bukan dalam artian paradigma baru, maupun mereka tertolak.

- Berbagai standar untuk mengevaluasi teori-teori ilmiah berkembang bersamaan denganberbagai problem sehingga satu teori harus menyesuaikan dengan paradigm solve.

Misalnya: Fisika Newtonian memperkenalkan satu unsur "ghaib" yaitu gaya(forces), terhadap pandangan yang berlaku dari pandangan sel hidup (corpuscular) bahwa semua penjelasan fisik harus dalam hal tumbukan (collisions) dan interaksi fisikal yang lain di antara partikelpartikel. Teori Newton tidak sesuai dengan standar ini, tetapi teori tersebutmemecahkan banyak problem terkemuka. (Pandangan corpuscular tidak dapat menjelaskan selain dalam cara kualitatif kasar mengapa planetplanet bergerak dalam orbit; Hukum Kepler memisahkan deskripsi tentang mengapa 
demikian. Oleh karena itu merupakan prestasi besar ketika mempostulatkan gaya mengambil derivasidari Hukum Kepler.)

"Gaya" sebagian besar diterima sebagai ganjil, semacam entitas "magis". Newton berusaha mengembangkan teori corpuscular tentang gravitasi, tetapi tidak berhasil, sebagaimana banyak ilmuwan Newtonian yang mengikuti jejak beliau. Akhirnya, ketika menyadari upayanya itu sia-sia, maka standar bahwa penjelasan corpuscular-mekanistik itu lalu diabaikan, dan atraksi gravitasional diterima sebagai intrinsik, sifat materi yang tidak dapat dijelaskan.

Misal lagi: Kimia sebelum Dalton bertujuan menjelaskan kualitas-kualitas sensoridari persenyawaan (warna, aroma, suara, dsb.). Paradigma atomis Dalton hanya cocok untuk menjelaskan mengapa persenyawaan ada bersama dalam proporsi tertentu; sehingga ketika itu diterima secara umum maka kebutuhan teoriyang menjelaskan kualitas-kualitas sensori diabaikan.

Misal lagi: (a) Phlogiston. Problem tantang menjelaskan bagaimana phlogiston dikombinasikan dengan calxes menjadi bentuk metal khusus ditinggalkan ketika phlogiston itu sendiri ditinggalkan. Ether (media untuk radiasi elektromagnetis); menjelaskan mengapa gerakan melalui ether tidak terdeteksi lenyap bersama dengan ether. Dalam hal ini tidal ada problem yang perlu dipecahkan.

(b) Percobaan Michelson-Morley. Percobaan ini pertama-tama "dijelaskan" oleh Lorenz berdasarkan teorinya tentang elektron, yang mengandaikan bahwa karena gaya bersama materi merupakan elektromagnetis dan oleh karenanya dipengaruhi oleh gerak melalui ether, maka bagian-bagian benda kontraksi dalam arah gerak ketika bergerak melalui ether. Relativitas menjelaskan kontraksi, tetapi dalam kerangka konseptual baru yang tidak meliputiether.

- Beberapa entitas baru diperkenalkan bersama dengan paradigma; sebenarnya hanya menjadi masuk akal (dapat dikonseptualisasikan) ketika entitas tersebut diperkenalkan. (misal Oksigen tidak "ditemukan" sampai teori oksigen tentang pembakaran combustion dikembang-kan).

- Unsur-unsur yang dipertahankan mungkin mempunyai status yang sama sekali berbeda. (Konstanta kecepatan cahaya merupakan postulat dalam teori relativitas khusus, sebagai konsekuensidariteori Maxwell.) Tesistesis konseptual substantif mungkin diperlakukan sebagai "tautologis" (misal Hukum Newton II).

Fakta menunjukkan bahwa berbagai standar, konsep, dan gambaran metafisika baru diperkenalkan menjadi-kan paradigmaparadig mabukan hanya tidak cocok, tetapi juga tidak dapat diperbandingkan (incommensurable). Paradigm shift adalah pergeseran pandangan dunia.(http://www.soc.ia state. edu/sapp/phil_sci_lecture11.html).

\section{PERBANDINGAN PANDANGAN POPPER DAN KUHN}

Pada dasarnya posisi Popper memainkan peranan utama dari seorang ilmuwan yang baik dengan mengkritik atas kemapanan maupun bekerjanya hipotesis. Sifat yang paling khas dari metode ilmiah bahwa para ilmuwan akan melakukan segala cara untuk mengkritik dan menguji teori. Mengkritik dan menguji itu berjalan beriringan, teori ini dikritik dari berbagai sudut pandang yang berbeda dalam rangka untuk membawa keluar titik-titik yang mungkin rentan (https://www.academia. edu/7491614/KARL_POPPER_VERSUS THOMAS_KUHN).

Bagan 5. Kerja ilmuwan dan fungsi ilmu ala Popper 


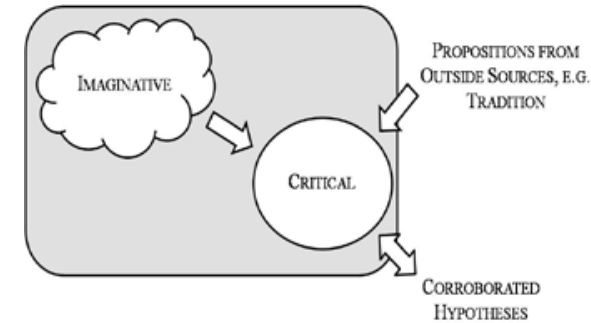

Sumber : Darrell.Rowbottom @philosophy.ox.ac.uk

Pandangan Kuhn di lain pihak bahwa kritik merupakan pengecualian (exceptional); yang membawa pada terjadinya paradigm shift dan "puzzled solving" dalam ilmu maupun "normal science". Kegagalan untuk mencapai satu solusi hanya akan mendiskreditkan para ilmuwan dan bukan pada teori. Kuhn boleh jadi benar, bahwa sebagian besar waktu jangan untuk menanyakan kaidah (rules), akan tetapi jika kaidah tidak pernah ditanyakan maka kita tidak akan memiliki eksplanasi atas terjadinya paradigm shifts itu sedari awal, oleh karena itu Kuhn memberi kita gambaran tentang bagaimana ilmu bekerja. Popper dan Kuhn tidak sepaham tentang fungsi dalam praktikilmu, yang satu menyebutnya sebagai kritik (Popper) dan yang lain menyebut sebagai puzzle solving (Kuhn).

Bagan 6. Kerja ilmuwan dan fungsi ilmu ala Kuhn

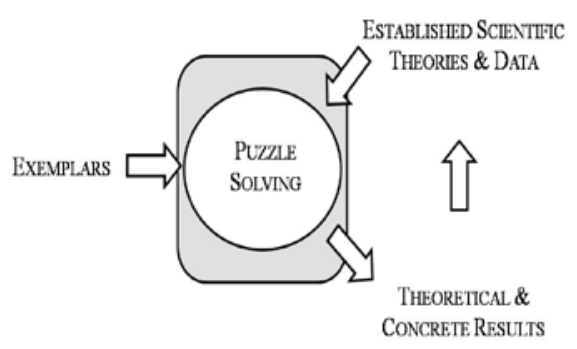

Sumber:Darrell.Rowbottom

@philosophy.ox.ac.uk

Para ilmuwan lain melihat hubungan antara pandangan Popperdan Kuhn karena kedua pandangan tersebut memotret beberapa aspek dari kemajuan ilmu. Pandangan Kuhn tentang hakikat dan kemajuan ilmu merupakan perkembangan socio-psychological dari pandangan Popper. Sementara itu Popper berkonsentrasi pada aspek hypothetico-deductive dari ilmu ini pada dasarnya terlalu menyibukkan diri pada kajian teoretis (lihat Widisuseno, 2006: 154), Kuhn merambah faktor-faktor sosial dan psikologis berkenaan dengan aktivitas ilmuwan. Tampaknya Popper dan Kuhn sepaham bahwa ilmu bukan berlangsung melalui induction. Akan tetapi Kuhn tidak sepaham dengan pandangan bahwakemajuan ilmu dicapai melalui siklus conjectures dan refutations (https://www.academia.edu/7491614/KAR L_POPPER_VERSUS_THOMAS_KUHN)

Bagan 7. Model hibrida: Fungsi ilmu pada level kelompok

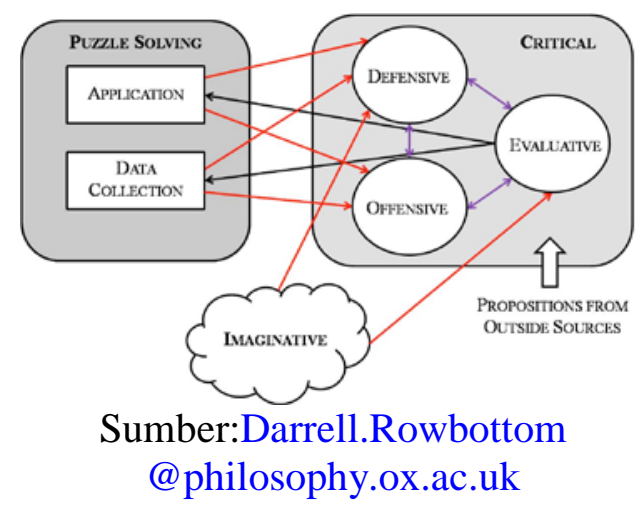

Perdebatan tentang manakah fungsi ilmu itu lebih penting untuk dibahas dalam konteks individual ilmuwan, tetapi baik Popper dan Kuhn jelas kehilangan solusi: kedua fungsi bekerja (performed) pada group level, yaitu, dengan sekelompok ilmuwan bekerja dalam satu disiplin (ilmu) khusus. Beberapa ilmuwan lebihmeningkat kepeduliannya terhadap kritikdan ilmuwan lain peduli pada puzzle solving. Ilmu bekerja dengan baik karena terdapat pembagian kerja yang memfasilitasi interaksi berkelanjutandi antara dua fungsi tersebut.
V. INSPIRASI DARI POPPER DAN KUHN UNTUK PENGAJARAN DAN PENGEMBANGAN ILMU 
Di satu pihak, pandangan Popper tentang kemajuan ilmu berimplikasi dalam pengajaran ilmu. Implikasi pertama mengandaikan bahwa pengajar harus mendorong objektivitas, penalaran logis dan pengembangan ketrampilan pemecahan masalah (problem solving skills). Pembelajar dalam kelompok dapat membuat usulan teori-teori dan melalui diskusi dicoba untuk falsify teori dari kelompok lain sehingga menjadikan pengajaran dan pembelajaran ilmu menarik dan bermanfaat. Implikasi kedua meng-andaikan bahwa pengajar harus menumbuh-suburkan sikap di antara pembelajar bahwa semua ilmu bersifat tentatif, dan diperlukan usaha terusmenerus untuk menemukan ide-ide yang lebih kuat melalui pemikiran dan penyelidikan kritis (https://www.academia.edu/7491614/KAR L_POPPER_VERSUS THOMAS_KUHN).

Pada gilirannya, pandangan Kuhn berimplikasi pula dalam pendidikan ilmu. Implikasi pertama mengandaikan bahwa pengajarharus membantu pembelajarmeraihpengetahuandalamilmum elaluikombinasi kegiatan problem solving. Pembelajarharus diberi berbagai eksperimendan dipandu melakukan berbagai observationdan konklusi. Observasidan pengujianyang berulang-ulang akan mengantarkan mereka pada penemuan dengan keterlibatan diri mereka. Implikasi kedua mengandaikan bahwa pengajar harus menjadi role modelsbagi pembelajar. Selanjutnya pengajar menjadi pemandu agar pembelajar melakukan berbagai investigasi atas isu-isu yang berkaitan dengan ilmu.

Akhirnya, menarik perhatian kita untuk melakukan refleksi sejauh mana praktik pengajaran ilmu pada pendidikan dasar sampai pendidikan tinggi di lingkungan kita telah menerapkan pendekatan integral-komprehensif dan mendasarkan diri pada budaya bangsa? Diperlukan kajian tentang ketepatan content dan metode pembelajaran kurikulum terbaru 2013 dalam rangka menyediakan ruangruang bagi para pembelajar untuk mengaktualisasikan potensi dirinya secara penuh. Lebih dari itu, diperlukan politik pendidikan untuk memajukan dunia pendidikan di Indonesia secara signifikan dalam rangka penguatan daya saing sumber daya manusia, terutama akses pendidikan bagi anak bangsa yang lemah dan terpinggirkan. Pendidikan sejatinya proses pembebasan dari kondisi kekurangan dan ketertindasan yang membelenggu diri sehingga memungkinkan anak bangsa ini menyongsong hari esok yang lebih baik. 


\section{DAFTAR PUSTAKA}

Kuhn, Thomas S. (1996). The Structure of Scientific Revolutions. Chicago: The University of Chicago Press.

Pajares, F. (n.d.).Kuhn's Structure of Scientific Revolutions. Diunduhdarihttp://www.des.emory.ed u/mfp/Kuhn.html

Philosophy of Science. Diunduhdarihttp: //www.en.wikipedia.org/wiki/phlosop hy_of_science

Pillos,Stathis. (1995). “Theory, Science and Realism”. Lecture Notes.

Popper, Karl R. (1959). The Logic of Scientific Discovery. New York: Basic Books.

Popper and Philosophy of Education. Diunduh dari http://www.ffst.hr /ENCYCLOPAEDIA/doku.php?=pop per_and_phylosophy_of_education.

Rowbottom, Darrell P. "Kuhn vs. Popper on Criticism and Dogmatism in Science: A Resolution at the Group Level", Faculty of Philosophy, University of Oxford.

Darrell.Rowbottom@philosophy.ox.a c.uk
Thomas Kuhn's Philosophy of Science. Diunduh dari http://www.wsws.org/ articles/2011/oct 2011/kuhn_028.html.

Widisuseno, Iriyanto. (2006). Teori Pertumbuhan Pengetahuan Ilmiah Karl R. Popper (Epistemologi Evolusioner) dan Penerapannya di Indonesia. Semarang: BP UNDIP.

Wutrich, Christian. 2013."Popper, Kuhn, Lakatos and Fayerabend". Philosophy of Science lecture notes University of California at San Diego.Diunduh dari http://philosophy. ucsd. du/faculty/ wuthrich/

Zynda, Lyle. 1994. "Carnap vs Popper”. Introduction to Philosophy of Scince lecture notes Princetown University. Diakses dari http://www.soc.astate.edu/sapp/phil_sci lecture08.html "Anomaly, Crisis, and the Non-Comulativity of Paradigm Shift". Introduction to Philosophy of Science lecture notes Princetown University. Diakses dari http://www.soc.iastate.edu/sapp/phil sci_lecture11.html

https://www.academia.edu/7491614/KARL _POPPER_VERSUS_THOMAS_KU HN 